\title{
Threading Immobilized DNA Molecules through a Solid-State Nanopore at $>100 \mu s$ per Base Rate
}

\author{
Changbae Hyun, Harpreet Kaur, Ryan Rollings, Min Xiao, and Jiali Li ${ }^{*}$ \\ Department of Physics, University of Arkansas, Fayetteville AR 72701
}

\begin{abstract}
In pursuit of developing solid-state nanopore based DNA sequencing technology, we have designed and constructed an apparatus that can place a DNA tethered probe tip near a solid-state nanopore, control the DNA moving speed, and measure the ionic current change when a DNA is captured and released from a nanopore. The probe tip's position is sensed and controlled by a tuning fork based feedback force sensor and a nanopositioning system. Using this newly constructed apparatus, a DNA strand moving rate of $>100 \mu \mathrm{s} / \mathrm{base}$ or $\langle 1 \mathrm{~nm} / \mathrm{ms}$ in silicon nitride nanopores has been accomplished. This rate is 10 times slower than by manipulating DNA tethered beads using optical tweezers and 1000 times slower than free DNA translocation through solid-state nanopores reported previously, which provides enough temporal resolution to read each base on a tethered DNA molecule using available single channel recording electronics on the market today. This apparatus can measure 3 signals simultaneously: ionic current through a nanopore, tip position, and tip vibrational amplitude during the process of a DNA's capture and release by a nanopore. We show results of this apparatus for measuring $\lambda$ DNA's capture and release distances, and for current blockage signals of $\lambda$ DNA molecules biotinylated with one end and with both ends tethered to a tip.
\end{abstract}

\section{Keywords}

Solid-state nanopore; DNA; probe tip; tuning folk; tethered DNA translocation; nanopositioning; DNA capture distance

Since voltage biased protein channels were demonstrated to be capable of detecting single stranded DNA and RNA molecules 15 years ago, ${ }^{1}$ and 5 years later solid-state nanopores were fabricated to overcome the stability of protein membrane structures, ${ }^{2-4}$ nanopore technology has become a fast increasing field due to its potential application in single molecule DNA sequencing ${ }^{5-7}$ and its applications in characterizing single protein molecules at their native and denatured states. ${ }^{8-16}$ When a nanopore in an insulating membrane is immersed in an electrolyte and a voltage is applied across the membrane, the flow of ions through the pore generates an open pore current. A DNA molecule nearby can be captured and driven through by the electric field of the pore. The passing of a DNA molecule partially blocks the flow of ions, producing a current drop event characterized by

\footnotetext{
”jialili@uark.edu.

Supporting Information

Additional data sets and figures are included in the Supporting Information. This material is available free of charge via the Internet at http://pubs.acs.org.

Author Contributions

C. Hyun contributed to the design, performing, and writing, H. Kaur contributed to the tip and DNA molecule preparation, R. Rollings contributed to the nanopore preparation and writing, M. Xiao supported the experiments, J. Li conceived the experiment, contributed to the design and writing.
} 
its magnitude and time duration. Much effort has been devoted to increase both the current drop magnitude and time duration to improve the spatial and temporal resolution of a nanopore device for the ultimate goal of reading DNA sequence electrically and for single molecule proteomics. These efforts include decreasing nanopore thickness and increasing DNA translocation time. ${ }^{17-25}$ In this work we report a technique developed to overcome one of the major obstacles in nanopore single DNA and protein analysis: controlling the moving speed of a biomolecule in a nanopore by integrating a solid-state nanopore device with a DNA tethered probe tip that is position controlled and sensed by a nanopositioning system and a tuning fork based force sensor.

As reviewed by Keyser et $\mathrm{al}^{22}$, many research groups have tried to control the speed of DNA transport through a nanopore by modifying the translocating molecule ${ }^{26}$ the nanopore, ${ }^{27}$ or mechanically manipulating the DNA molecules. ${ }^{28,}{ }^{29}$ Mechanically manipulating DNA molecules has been performed by DNA-tethered beads suspended in solution and controlled either by optical tweezers or by a magnetic trap. The optical tweezers method, which traps a DNA-tethered bead in the crossover of a focused laser beam, can manipulate the DNA-tethered bead in three-dimensions and has a pico-newton range of force sensitivity. However, heating due to the laser in optical tweezers increased the ionic current through a nanopore and noise, ${ }^{30,31}$ requiring the optically trapped bead to be several micrometers away from a nanopore. Furthermore, the bead trapping methods also have Brownian motion problem that makes it difficult to control the motion of the bead with less than $10 \mathrm{~nm}$ resolution. In contrast, a scanning probe tip in an AFM or SNOM based system can approach more closely to a nanopore and can have sub-nanometer spatial resolution as reported recently. ${ }^{32,33}$

Motivated by controlling the speed of DNA translocation in a nanopore at a rate of $\sim 100 \mu \mathrm{s} /$ base or slower for developing solid-state nanopore based DNA sequencing technology, we have designed and constructed an apparatus as shown in Figure 1a. This apparatus combines the measurement of ionic current through a solid-state nanopore with a DNA tethered probe tip that it is position controlled and sensed by a tuning fork force sensor and a nanopositioning system. We report here that by using this newly constructed apparatus that integrates a Solid-state Nanopore and a Tuning Fork based Force Sensing Probe tip, SSNTFFSP, by tethering $\lambda$ DNA molecules to the probe tip, a DNA translocation speed of $\sim 400$ $\mu \mathrm{s} / \mathrm{base}$ or $1 \mathrm{~nm} / \mathrm{ms}$ in a solid-state nanopore has been accomplished. This speed is 10 times slower than the optical trapping DNA tethered bead method reported ${ }^{34}$ and 1000 times slower than free DNA translocation through solid-state nanopores. , 5, 7, 35 We will first describe the details of this SSN-TFFSP apparatus. We then show the current blockage traces caused by tethered $\lambda$ DNA being captured by a nanopore, and the process of DNA being pulled out by a TFFSP tip. We show the $\lambda$ DNA's most probable capture and release distances measured by this SSN-TFFSP system and show that these results are consistent with the radius of gyration and the contour length of $\lambda$ DNA molecules in solution. Furthermore, we present current blockage signals of $\lambda$ DNA biotinylated with one end and with both ends tethered to a tip measured by this apparatus.

\section{EXPERIMENTAL SETUP}

Figure 1a shows a schematic diagram of the integrated solid-state nanopore and tuning fork force sensor based probing (SSN-TFFSP) system constructed for this work. A DNA molecule is tethered to a TFFSP tip that is glued to one prong of a quartz tuning fork. The tuning fork is attached to a piezo actuator that is affixed to a XYZ piezo positioner (Nanopositioner, Mad City Labs, not shown in the diagram). The TFFSP tip's position in solution is sensed by the tuning fork sensor and is controlled by the XYZ Nanopositioner. The vibration amplitude of the tuning fork is sensitive to the viscous drag in solution and the 
sheer force when the tip is close to a surface. A nanopore chip containing a window of 30 $\mu \mathrm{m}$ free standing silicon nitride membrane with a $\sim 10 \mathrm{~nm}$ pore at its center (Fig. $1 \mathrm{~b}$ shows a TEM image and 1c shows its thickness profile) divides the electrolyte solution into two sections: cis and trans chambers, which are made of glass sealed with PDMS (not shown). The sole electrical and fluidic connection between the two chambers is the nanopore. The electrolyte solution used in this work is $1 \mathrm{M}$ potassium chloride $(\mathrm{KCl})$ with $10 \mathrm{mM}$ Tris at $\mathrm{pH}$ 8. The ionic current through the pore is measured by a pair of $\mathrm{Ag} / \mathrm{AgCl}$ electrodes in each chamber. The ionic current is measured and recorded with the Axopatch 200B integrated amplifier system (Molecular Devices) with its low pass Bessel filter set at $2 \mathrm{kHz}$ in this work. The sample holder that holds a pair of cis and trans chambers with a nanopore chip sandwiched in between is mounted on a manual XYZ micro-manipulator. The whole SSN-TFFSP system is shielded by a Faraday cage.

After a nanopore is tested with reasonable open pore current and noise level, the DNA attached tip is immersed in the cis chamber. When the tip is near the nanopore, one or more DNA molecules can be captured by the electric field extended outside of the nanopore $^{32,33,36,37}$ and pulled into the nanopore until the captured DNA molecule is stretched and held by the tethering force from the TFFSP tip. A DNA molecule near or inside a nanopore partially blocks the flow of ions, increases the pore resistance, and produces an observable drop in pore current. When the captured DNA molecule is pulled out from the nanopore by the probe tip, the pore current recovers. By observing these current drops and recoveries, the process of capturing and releasing tethered DNA molecules by a nanopore can be measured. Details of the main components of this SSN-TFFSP system, sample preparation, and the experiment to be performed are described in the Methods section.

\section{RESULTS AND DISCUSSION}

Figure 2 shows that the integrated SSN-TFFSP system can measure three parameters vs time simultaneously: 1) the ionic current through the nanopore (Fig. 2a), 2) the tip distance above the membrane surface (Fig. 2b), and 3) the vibration amplitude of the tuning fork (Fig. 2c). The ionic current in figure $2 \mathrm{a}$ was measured by applying $60 \mathrm{mV}$ across the nanopore shown in Figure 1b. The stable open pore current was $16 \pm 0.7 \mathrm{nA}$, which was larger than expected from the $10 \mathrm{~nm}$ diameter pore shown in Fig. 1b. The diameter of the pore in solution was estimated to be about $20 \mathrm{~nm}$ judging by the open pore current. Figure $2 \mathrm{~b}$ shows that the tip's end was initially $32 \mathrm{um}$ above the nanopore surface. As the tip was approaching the nanopore from the starting time of (i), the vibration amplitude of the tuning fork decreased slightly since the tip's immersion depth increased (Fig. 2c). When the probe tip was at $\sim 2 \mu \mathrm{m}$ distance above the pore at time (ii), a drop in ionic current occurred, indicating possibly a tethered DNA molecule was captured by the nanopore electric field. When the tip was brought closer to and engaged to the membrane near the pore, its vibration amplitude decreased abruptly at the time of (iii) due to increased shear force (the tip was not right on top of the pore, it was placed a little bit away from the nanopore but within DNA capture distance). The tip stayed on the membrane from the time of (iii) to (v), and started to move up at the beginning of time (v). The current noise increased when the tip was on the membrane (see Figures SI_1, 2, 3, 4, and 11 in Supporting Information for more recorded traces), possibly caused by the tip's mechanical vibration that disturbed ionic current flow to the pore. This interpretation is consistent with the observation that this vibration related current noise was absent before the tip had interacted with the membrane and after the tip had moved up from the membrane. When the tip was at $12.7 \mu \mathrm{m}$, and $15.8 \mu \mathrm{m}$ above the pore, the pore current stepped up with $\Delta_{2}=43 \mathrm{pA}$ at (vi) and $\Delta \mathrm{I}_{1}=23 \mathrm{pA}$ at (vii). The ionic current recovered to its original value at time (vii). The tip was lifted to its starting position at time (viii). This experiment, tethered DNA molecules on a probe tip approaching the 
same nanopore then pulling up by the nanopositioner, was repeated more than 10 times with the same nanopore and tip (see Figures SI_1 to SI_7 in SI). Most of these measurements show multiple steps of current drop and recovery. The statistics of the first capture and last release distances are shown in Figure 3. The statistics of the magnitudes of the current drop and recovery steps are shown in Figure $4 \mathrm{a}$.

During measurements, parameters were adjusted to avoid biotin-streptavidin rupture. ${ }^{38}$ After applying a $500 \mathrm{mV}$ voltage across a nanopore for a few seconds right after a DNA molecule was captured by a nanopore at a $60 \mathrm{mV}$ bias voltage, the DNA capture events couldn't be measured again, possibly due to the rupture between biotin-streptavidin bonding. The biotinstreptavidin bonding could also break when the tip was pulled too fast even at a $60 \mathrm{mV}$ bias voltage, for example, lifting the tip $10 \mu \mathrm{m}$ up within $100 \mathrm{~ms}$ after a tethered DNA molecule was trapped inside a nanopore.

The DNA's capture distance by the electric field extended outside of a nanopore can be measured in this SSN-TFFSP system in a similar way to those discussed by other groups using optical tweezers. ${ }^{34,39}$ At time (ii) in Figure 2, current drop occurred before the tip was engaged to the membrane. The distance moved by the tip between (ii) and (iii) was $\sim 1.8 \mu \mathrm{m}$, indicating the capture distance. The measured capture distances in this experiment are shown in Figure $3 \mathrm{a}$. The average of the capture distances in Figure $3 \mathrm{a}$ is $1.1 \pm 0.6 \mu \mathrm{m}$. This value is comparable to $\lambda$ DNA's radius of gyration, $\sim 1 \mu \mathrm{m} / 2=0.5 \mu \mathrm{m}$. We also measured the tip's moving distance from the starting time of $(v)$ to the time at which DNA was released (vii) as shown in Figure 3b. The average last release distance is about $15.0 \pm 1.2 \mu \mathrm{m}$, very close to the contour length of a $48.6 \mathrm{kbp} \lambda$ DNA $(16.4 \mu \mathrm{m})$ molecule. The spanning time between (v) and (vii) was $21.4 \mathrm{sec}$, thus the DNA translocation speed as it was retracted from the pore was $0.73 \mu \mathrm{m} / \mathrm{s}$ or 1 base/ $400 \mu \mathrm{s}$. This rate is 10 times slower than

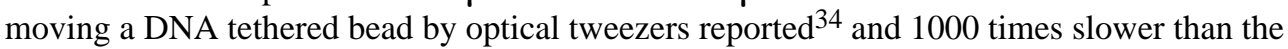
reported free DNA translocation through solid-state nanopores $4,5,7,35$. If we set the tip's moving up time from (v) to (viii) to be as slow as the tip's approaching time from (i) to (ii) (Fig. 2), the DNA translocation speed in a nanopore could reach as slow as $0.4 \mu \mathrm{m} / \mathrm{s}$ or 1

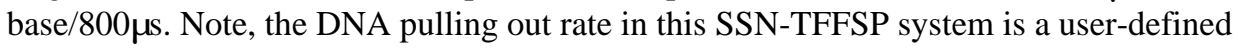
parameter for the nanopositioning system, practically no upper limit.

The time resolution of a nanopore device is determined by the DNA translocation speed and the bandwidth of the current recording electronics. Considering the highest bandwidth for a typical nanopore current recording system available on the market is $\sim 100 \mathrm{kHz}(\sim 10 \mu \mathrm{s})$, and most published DNA translocation data were recorded at 10 or $100 \mathrm{kHz}(\sim 100 \mu \mathrm{s})$, the speed of 1 base $/ 400 \mu$ s would provide enough temporal resolution to read each base on a tethered DNA molecule. This experiment had demonstrated that the newly constructed SSNTFFSP system has obtained the time resolution required to electrically read a DNA's sequence.

After DNA was pulled out of the nanopore at the times (v) and (vii) shown in Figure 2, the ionic current recovered to its original open pore value. The amplitudes of current recoveries are shown in Fig. 4a. The histogram of the current recoveries in Fig. 4a shows two peaks with the average values of $23.8 \pm 2.0 \mathrm{pA}$ and $43.4 \pm 3.4 \mathrm{pA}$ instead of a single peak. Considering the current changes $\Delta \mathrm{I}_{2}=43 \mathrm{pA}$ and $\Delta \mathrm{I}_{1}=23 \mathrm{pA}$ are not the same, and this $\Delta \mathrm{I}_{1}=23 \mathrm{pA}$ was often corresponding to "sticking events" or events with no DNA pulling out process observed from time (V) to (vi) (see Fig SI_8, 9, 12), we assume that the $\Delta \mathrm{I}_{1}=23 \mathrm{pA}$ was caused by a DNA sticking near the nanopore surface and the $\Delta_{2}=43 \mathrm{pA}$ occurred at (iv) was a real DNA translocation through the nanopore as illustrated on top of Fig. 2. Below we discuss why this assumption is reasonable and why we had observed two or even more steps during the processes of current drop and recovery. 
As described in the method section of tethering DNA to a tip, many copies of $\lambda$ DNA can attach to a tip. Therefore two or more copies of $\lambda$ DNA molecules could be captured by a nanopore. This is also consistent with our observations shown in Fig. 2 and the Figures in Supporting Information. To further estimate the approaching process and the amount of current blocked from an approaching DNA at different DNA-nanopore distances, we have simulated the current drop amplitudes using a finite element analysis program (COMSOL, Multiphysics).

To estimate the current drop magnitude induced by a DNA molecule near or inside a nanopore, we have used Nernst-Planck and Poisson equations (COMSOL). The NernstPlanck equation describes the flux of chemical ions (potassium and chloride ions) under the influence of an electric field in solution under user defined nanopore geometries. The electrical field and the electrical potential generated in ionic solution are described by the Poisson equation. Using these equations and the nanopore geometry shown in Fig. 1c with or without DNA, we can solve for the flux of the chloride ions and potassium ions through the pore. The current is then found by the integration $I=\int F\left(J_{C l}+J_{K}\right) d A$, where $F$ is the Faraday constant, $\mathrm{A}$ is the cross-sectional area of the pore with or without DNA, and $\mathrm{J}_{\mathrm{Cl}}$ is chloride ion's flux, and $\mathrm{J}_{\mathrm{K}}$ is potassium ion's flux. Fully solving for current in this way considers the access resistance of the nanopore, ${ }^{33,40}$ as well as the geometry of the tapered nanopore wall shown in Fig. 1c. The detailed calculation of current passing through a nanopore is explained in our earlier report. ${ }^{33}$

In this simulation, a double stranded DNA molecule was assumed to be a 2.2-nm-diameter rigid cylinder, and the thickness profile data in Fig. 1c for the geometries of a nanopore and freestanding membrane were used. To match the experimentally measured open pore current, a $26 \mathrm{~nm}$ diameter pore was used in this simulation. Fig. $4 \mathrm{~b}$ shows the amount of DNA-induced current drop as the DNA-nanopore distance changed. The insets in Fig. 4 show two of the DNA-nanopore configurations for the simulation. The DNA-nanopore distance in Fig. 4b is defined from membrane's top surface to the DNA cylinder's front end. The current blockage started when the front end of the DNA was about $50 \mathrm{~nm}$ above the nanopore (top left, Fig. 4b), consistent with the concept of nanopore access resistance. The current blockage reached a maximum of $43 \mathrm{pA}$ when the cylinder's bottom is $200 \mathrm{~nm}$ below the nanopore entrance, the very end of the FIB hole region. This value matches to the right peak in Fig. 4a of the experimental data. When the DNA cylinder's front end is right above the nanopore, the current blockage is $25 \mathrm{pA}$. Based on these two current blockage numbers, a possible interpretation is that the left peak in Fig. 4a is related to DNA's sticking to the nanopore's entrance without translocating. This is also consistent with many DNA sticking or collision events observed during solid-state nanopore experiments when tether-free DNA were used in our lab (data not shown) and reported by other groups ${ }^{41}$.

The above simulation is based on that volume exclusion is the only mechanism for DNAinduced current blockades $\Delta \mathrm{I}_{\mathrm{b}}$, earlier reports have shown that other parameters also contribute to the magnitude of current blockades. Reiner et al $^{42}$ proposed that the ionic current can be reduced not only by DNA volume exclusion but also by ion exclusion due to cation binding to DNA inside a pore. To further understand and more precisely calculate the interactions of a DNA molecule with a nanopore in our future experiments, Reiner's proposal may be necessary. Furthermore, We have also ignored how asymmetrical charge distribution influences ionic current through a nanopore as reported in a study of protein pores. ${ }^{43}$ Based on our previous study, the surface charge's influence on the ionic current through a $25 \mathrm{~nm}$ diameter nanopore in $1 \mathrm{M} \mathrm{KCl}$ was negligible. ${ }^{33}$ therefore we did not consider nanopore's surface charge effects on current blockade caused by DNA translocation through a pore. In summary, the absolute DNA blocked current could also dependent on the pore geometry, ion binding to DNA, as well as surface charge on a 
nanopore. In this simulation, we consider only the volume exclusion to provide qualitative values of blocked current $\Delta \mathrm{I}_{\mathrm{b}}$ as a function of DNA-nanopore position (Fig. 4b) to estimate the DNA-nanopore configuration.

To further verify the current drop and recovery steps were produced by DNA molecules interacting with a nanopore, we have attached both ends biotinylated $\lambda$ DNA molecules to the probe tip. In addition to the current drop and recovery steps observed in Fig. 4b, larger current drop and recovery steps were observed (see Figures SI_10,_11). The current blockage histogram using the both-ends-biotinylated is shown in Fig. 5. As we expected, the current blockage histogram shows three distinctive groups. The left group has $\Delta_{1}=22.9 \pm$ $2.0 \mathrm{pA}$, possibly corresponding to DNA's incomplete translocation as depicted on top left of Fig. 5. The center group has $\Delta_{2}=43.8 \pm 4.5 \mathrm{pA}$, possibly related to one $\lambda$ dsDNA translocation with only one-end anchored to the tip. The right group has $\Delta \mathrm{I}_{3}=83.3 \pm 5.6 \mathrm{pA}$, which would match a double-anchored $\lambda$ DNA as shown on the top right of Fig. 5. This further demonstrates that the $45 \mathrm{pA}$ current drop is most likely caused by a dsDNA translocation in the pore. Shorter release distances expected for a double-anchored $\lambda$ DNA were not consistently observed. A possible explanation is that a U shaped DNA molecule is difficult to be pulled out due to the pore-DNA interaction, thus often broke off from the tip and trapped in the pore as we observed (see Figure SI_10 and SI_11)

\section{CONCLUSION}

In this work, we report a novel method that is capable of controlling DNA translocation speed in a solid-state nanopore to the order of $\sim 100 \mu$ s/base by tethering $\lambda$ DNA molecules to a probe tip. The tip's position is sensed and controlled by a tuning-folk-based force sensor and by a nanopositioning system. This SSN-TFFSP system can bring a DNA tethered TFFSP tip close to a nanopore, monitor the capture process of a DNA molecule by a voltage-biased nanopore, and most importantly, pull a captured and trapped DNA out of the nanopore with a controlled speed and sub-nanometer accuracy. The measured DNA's capture and release distances are comparable to the gyration diameter and the contour length of the $48.5 \mathrm{kbs} \lambda$ DNA respectively. The recorded current signals show the expected current drop and recovery steps for one end and for both ends biotinylated $\lambda$ DNA molecules. In addition, current traces also revealed that some DNA molecules did not translocate completely through a nanopore, but stay near the nanopore's entrance. This was also supported by finite element analysis computer simulation. This SSN-TFFSP system has demonstrated the capability of slowing down DNA moving speed in a pore more than 1000 times compared to tether-free DNA translocation through solid-state nanopores, which allows studying DNA-nanopore interaction in great details, and provides enough temporal resolution to read each base on a tethered DNA molecule in the future.

Furthermore, this system potentially can have many other applications in the field of manipulation and detection single DNA and protein molecules. The SSN-TFFSP system has the following advantages: controlling the motion of biomolecules at Angstrom precision with user defined moving speed, characterizing single DNA and protein molecules with solid-state nanopores and possibly protein pores, and using very small number of biomolecules. A few such examples of its applications include measuring DNA hybridization, RNA-protein and DNA-protein interactions, and single protein molecules in nanopores.

\section{Methods}

The quartz tuning fork (Fox electronics, NC38LF-327) shown in Fig. 1a is used as a force feedback sensor as demonstrated by other reports. ${ }^{44,45}$ By attaching a tip to one prong of a 
tuning fork, this device can be used as a force feedback sensor. ${ }^{46,47}$ The detailed tuning fork set up is reported in our another work. ${ }^{48}$ Briefly, at the resonance frequency, the vibration of the quartz tuning fork generates a small voltage, a few $\mathrm{mV}$. This vibration amplitude is sensitive to the viscous drag in solution and the shear force when the tip is close to a surface. This voltage signal is 1000 times pre-amplified and its amplitude is measured by a lock-in amplifier (Stanford Research Systems, SR850). The same lock-in amplifier is also used to generate the driving voltage for the piezo actuator. The oscillation amplitude of the tuning fork is estimated that the output voltage/displacement is $0.18 \mathrm{mV} / \mathrm{nm}$ by considering quartz's properties and tuning fork's geometry. ${ }^{48,49}$

The probe tip is made from a single mode optical fiber (Corning Optical fiber, SMF-28(TM)) using a micropipette puller (Sutter Instrument, P-2000). The pulled fiber tip is cleaned by Piranha solution (sulfuric acid: hydrogen peroxide $=3: 1$ ) for $10 \mathrm{~min}$, and then washed with DI water. The tip is coated with $250 \mathrm{~nm}$ thick chromium and gold using a sputter coater (Cressington, 108 auto). A typical $\mathrm{Cr} / \mathrm{Au}$ coated tip used in this report is shown in Figure 1d. The nanopores used in this study are fabricated in a free standing low stress silicon nitride membrane supported by a silicon substrate as described previously. ${ }^{2}$ The silicon rich, low stress silicon nitride membrane ( $275 \mathrm{~nm}$ in thickness) was deposited by low-pressure chemical vapor deposition (LPCVD) on both sides of the silicon substrate. One side of the silicon nitride membrane window is opened by procedures including photolithography, reactive ion etching, and anisotropic wet $\mathrm{KOH}$ etching to produce a freestanding silicon nitride membrane. A cavity of about $100 \mathrm{~nm}$ size is milled on the freestanding membrane window with a focused ion beam (FIB, Micrion 9500) machine, leaving a tapered membrane with a thickness of $20-30 \mathrm{~nm}$. Then a nanopore is drilled in the cavity using a high energy electron beam in a TEM (300 keV FEI Titan). The thickness profile across the nanopore in Figure 1c was measured by taking the log-ratio of an energy filtered zero-loss TEM image and unfiltered TEM image of the nanopore with $T=\lambda \ln \left(\mathrm{I}_{1} /\right.$ $\left.\mathrm{I}_{0}\right) .50$ Where $\lambda, \mathrm{I}_{1}$, and $\mathrm{I}_{0}$ are inelastic mean free path, unfiltered image intensity, and zeroloss intensity. The mean free path $\lambda$ is calculated empirically by measuring the thickness of the membrane using a standard optical reflectometer. We found $\lambda$ at $300 \mathrm{keV}$ to be $180 \mathrm{~nm}$ with errors of approximately $10 \%$. According to the thickness measurement, the silicon nitride membrane window is typically $210 \mathrm{~nm}$ thick and the cavity region is tapered to the nanopore by approximately $45^{\circ}$.

The $\lambda$ DNA (NEB, N3011S) are biotinylated following the procedures described by Keyser et al.. ${ }^{18}$ The one end biotinylated oligonucleotides (Integrated DNA Technologies) matching the known "overhang" sequence of $\lambda$ DNA were purchased. The $\lambda$ DNA and the biotinylated oligonucleotides were ligated with T4 ligase enzyme (NEB). A DNA extraction kit (QIAGEN, QIAEX II gel extraction kit) was used to purify the biotinylated $\lambda$ DNA after the ligation.

\section{Attaching Biotinylated $\boldsymbol{\lambda}$ DNA to the tip}

$\mathrm{The} \mathrm{Cr} / \mathrm{Au}$ coated optical fiber tip was immersed in a $10 \mathrm{mg} / \mathrm{ml}$ streptavidin (Invitrogen, 434301) solution for $10 \mathrm{~min}$. The depth of the tip in the solution was about 10-20 $\mu \mathrm{m}$. Streptavidin protein molecules were adsorbed to the Au coated tip during this process. The tip was then washed by DI water a few times to remove weakly adsorbed streptavidin. Fluorescently labeled streptavidin was used to verify the adsorption. The streptavidinadsorbed tip was then soaked in the biotin-labeled $\lambda$ DNA $(\sim 2 \mathrm{nM})$ for 10 min. After soaking the tip in the $\lambda$ DNA solution, the tip's end was kept in $1 \mathrm{M} \mathrm{KCl}$ solution during the experiment to avoid the detachment of DNA from the tip. To verify the $\lambda$ DNA molecules were attached to the tip by this method, we had further performed experiments to stretch the tethered DNA molecules by an AC electric field in salt solution under a fluorescent 
microscope ${ }^{48}$ The fluorescent images had shown that many copies of $\lambda$ DNA molecules are attached to the end of a tip by this procedure.

\section{Supplementary Material}

Refer to Web version on PubMed Central for supplementary material.

\section{Acknowledgments}

The authors thank Professor J. Golovchenko's nanopore group for FIB pore preparation, D. Tita, S. Nandivada, and N. Walsh for nanopore fabrication, R. W. Penhallegon for electronics support, Dr. M. Benamara for TEM imaging, Dr. Tao Huang for helping setting up the instrument, Prof. D. McNabb for helping DNA preparation. TEM related work was performed at the Arkansas Nano-Bio Materials characterization Facility. Support of this research has been provided by NHGRI/NIH R21HG004776, and partially supported by ABI1116.

\section{References}

1. Kasianowicz JJ, Brandin E, Branton D, Deamer DW. Characterization of Individual Polynucleotide Molecules Using a Membrane Channel. Proc Natl Acad Sci US A. 1996; 93:13770-13773.

2. Li J, Stein D, McMullan C, Branton D, Aziz MJ, Golovchenko JA. Ion-Beam Sculpting at Nanometre Length Scales. Nature. 2001; 412:166-169. [PubMed: 11449268]

3. Storm AJ, Chen JH, Ling XS, Zandbergen HW, Dekker C. Fabrication of Solid-State Nanopores with Single-Nnometre Precision. Nat Mater. 2003; 2:537-540. [PubMed: 12858166]

4. Li J, Gershow M, Stein D, Brandin E, Golovchenko JA. DNA Molecules and Configurations in a Solid-State Nanopore Microscope. Nat Mater. 2003; 2:611-615. [PubMed: 12942073]

5. Branton D, Deamer DW, Marziali A, Bayley H, Benner SA, Butler T, Ventra MD, Garaj S, Hibbs A, Huang X, et al. The Potential and Challenges of Nanopore Sequencing. Nature Biotechnology. 2008; 26:1146-1153.

6. Dekker C. Solid-state Nanopores. Nat Nanotechnol. 2007; 2:209-215. [PubMed: 18654264]

7. Venkatesan BM, Bashir R. Nanopore Sensors for Nucleic Acid Analysis. Nature Nanotech. 2011; 6:615-624.

8. Fologea D, Ledden B, McNabb DS, Li J. Electrical Characterization of Protein Molecules in a Solid-State Nanopore. Appl Phys Lett. 2007; 91:053901.

9. Oukhaled G, Mathe J, Biance AL, Bacri L, Betton JM, Lairez D, Pelta J, Auvray L. Unfolding of Proteins and Long Transient Conformations Detected by Single Nanopore Recording. Phys Rev Lett. 2007; 98:158101. [PubMed: 17501386]

10. Firnkes M, Pedone D, Knezevic J, Döblinger M, Rant U. Electrically Facilitated Translocations of Proteins through Silicon Nitride Nanopores: Conjoint and Competitive Action of Diffusion, Electrophoresis, and Electroosmosis. Nano Lett. 2010; 10:2162-2167. [PubMed: 20438117]

11. Niedzwiecki DJ, Grazul J, Movileanu L. Single-Molecule Observation of Protein Adsorption onto an Inorganic Surface. J Am Chem Soc. 2010; 132:10816-10822. [PubMed: 20681715]

12. Oukhaled A, Cressiot B, Bacri L, Pastoriza-Gallego M, Betton JM, Bourhis E, Jede R, Gierak J, Auvray L, Pelta J. Dynamics of Completely Unfolded and Native Proteins through Solid-State Nanopores as a Function of Electric Driving Force. ACS Nano. 2011; 5:3628-3638. [PubMed: 21476590]

13. Yusko EC, Johnson JM, Majd S, Prangkio P, Rollings RC, Li J, Yang J, Mayer M. Controlling the Translocation of Proteins through Nanopores with Bioinspired Fluid Walls. Nat Nanotechnol. 2011:253-260. [PubMed: 21336266]

14. Merstorf C, Cressiot B, Pastoriza-Gallego M, Oukhaled A, Betton JM, Auvray L, Pelta J. Wild Type, Mutant Protein Unfolding and Phase Transition Detected by Single-Nanopore Recording. ACS Chem Biol. 2012; 7:652-658. [PubMed: 22260417]

15. Wei R, Gatterdam V, Wieneke R, Tampé R, Rant U. Stochastic Sensing of Proteins with ReceptorModified Solid-State Nanopores. Nat Nanotechnol. 2012; 7:257-263. [PubMed: 22406921] 
16. Cressiot B, Oukhaled A, Patriarche G, Pastoriza-Gallego M, Betton J, Auvray L, Muthukumar M, Bacri L, Pelta J. Protein Transport through a Narrow Solid-State Nanopore at High Voltage: Experiments and Theory. ACS Nano. 2012; 6:6236-6243. [PubMed: 22670559]

17. Fologea D, Uplinger J, Thomas B, McNabb DS, Li J. Slowing DNA Translocation in a Solid State Nanopore. Nano Lett. 2005; 5:1734- 1737. [PubMed: 16159215]

18. Keyser, UF.; Does, Jvd; Dekker, C.; Dekker, NH. Inserting and Manipulating DNA in a Nanopore. In: Lee, JW.; Foote, RS., editors. Micro and Nano Technologies in Bioanalysis: Methods and Protocols. Humana Press; New York: 2009. p. 95-112.

19. Garaj S, Hubbard W, Reina A, Kong J, Branton D, Golovchenko JA. Graphene as a SubNanometer Trans-Electrode Membrane. Nature. 2010; 467:190-193. [PubMed: 20720538]

20. Merchant CA, Healy k, Wanunu M, Ray V, Peterman N, Bartel J, Fischbein MD, Venta K, Luo Z, Johnson ATC, et al. DNA Translocation through Graphene Nanopores. Nano Lett. 2010; 10:29152921. [PubMed: 20698604]

21. Schneider GF, Kowalczyk SW, Calado VE, Pandraud G, Zandbergen HW, Vandersypen LMK, Dekker C. DNA Translocation through Graphene Nanopores. Nano Lett. 2010; 10:3163-3167. [PubMed: 20608744]

22. Keyser UF. Controlling Molecular Transport through Nanopores. J R Soc Interface. 2011; 8:13691378. [PubMed: 21715402]

23. Wanunu M, Bhattacharya S, Xie Y, Tor Y, Aksimentiev A, Drndic M. Nanopore Analysis of Individual RNA/Antibiotic Complexes. ACS Nano. 2011; 5:9345-9353. [PubMed: 22067050]

24. Rosenstein, aK; Wanunu, M.; Merchant, CA.; Drndic, M.; Shepard, KL. Integrated Nanopore Sensing Platform with Sub-Microsecond Temporal Resolution. Nature Methods. 2012; 9:487-492. [PubMed: 22426489]

25. Kowalczyk SW, Wells DB, Aksimentiev A, Dekker C. Slowing down DNA Translocation through a Nanopore in Lithium Chloride. Nano Lett. 2012; 12:1038-1044. [PubMed: 22229707]

26. Manrao EA, Derrington IM, Laszlo AH, Langford KW, Hopper MK, Gillgren N, Pavlenok M, Niederweis M, Gundlach JH. Reading DNA at Single-Nucleotide Resolution with a Mutant MspA Nanopore and Phi29 DNA Polymerase. Nat Biotechnol. 2012; 30:349-353. [PubMed: 22446694]

27. Iqbal SM, Akin D, Bashir R. Solid-State Nanopore Channels with DNA Selectivity nature. Nanotech. 2007; 2:243-248.

28. Keyser UF, Koeleman BN, Dorp Sv, Krapf D, Smeets RM, Lemay SG, Dekker NH, Dekker C. Direct Force Measurements on DNA in a Solid-state Nanopore. Nature Physics. 2006; 2:473- 477.

29. Peng H, Ling XS. Reverse DNA Translocation through a Solid-state Nanopore by Magnetic Tweezers. Nanotechnology. 2009; 20:185101. [PubMed: 19420602]

30. Keyser UF, Krapf D, Koeleman BN, Smeets RM, Dekker NH, Dekker C. Nanopore Tomography of a Laser Focus. Nano Lett. 2005; 5:2253-2256. [PubMed: 16277463]

31. Smeets RMM, Keyser UF, Wu MY, Dekker NH, Dekker C. Nanobubbles in Solid-State Nanopores. Phys Rev Lett. 2006; 97:088101. [PubMed: 17026338]

32. King GM, Golovchenko JA. Probing Nanotube-Nanopore Interactions. Phys Rev Lett. 2005; 95:216103. [PubMed: 16384162]

33. Hyun C, Rollings R, Li J. Probing Access Resistance of Solid-State Nanopores with a ScanningProbe Microscope Tip. Small. 2012; 8:385-392. [PubMed: 22393313]

34. Trepagnier EH, Radenovic A, Sivak D, Geissler P, Liphardt J. Controlling DNA Capture and Propagation through Artificial Nanopores. Nano Lett. 2007; 7:2824-2830. [PubMed: 17705552]

35. Fologea D, Gershow M, Ledden B, McNabb DS, Golovchenko JA, Li J. Detecting Single Stranded DNA with a Solid State Nanopore. Nano Lett. 2005; 5:1905-1909. [PubMed: 16218707]

36. Wanuu M, Morrison W, Rabin Y, Grosberg AY, Meller A. Electrostatic Focusing of Unlabelled DNA into Nanoscale Pores Using Salt Gradient. Nature Nanotechnology. 2009; 5:160- 165.

37. Ando G, Hyun C, Li J, Mitsui T. Directly Observing the Motion of DNA Molecules near SolidState Nanopores. ACS Nano. 2012; 6:10090-10097. [PubMed: 23046052]

38. Tabard-Cossa V, Wiggin M, Trivedi D, Dwyer NNJJR, Marziali A. Single-Molecule Bonds Characterized by Solid-State Nanopore Force Spectroscopy. ACS Nano. 2009; 3:3009-3014. [PubMed: 19751064] 
39. Keyser UF, van der Does J, Dekker C, Dekker NH. Optical Tweezers for Force Measurements on DNA in Nanopores. Rev Sci Instrumen. 2006; 77:105105.

40. Hall JE. Access Resistance of a Small Circular Pore. J Gen Physiol. 1975; 66:531-532. [PubMed: 1181379]

41. Hout, Mvd; Krude, V.; Janssen, XJA.; Dekker, NH. Distinguishable Populations Report on the Interactions of Single DNA Molecules with Solid-State Nanopores. Biophys J. 2010; 99:3840 3848. [PubMed: 21112309]

42. Reiner JE, Kasianowicz JJ, Nablo BJ, Robertson JWF. Theory for Polymer Analysis Using Nanopore-Based Single-Molecule Mass Spectrometry. PNAS. 2010; 107:12080-12085. [PubMed: 20566890]

43. Noskov SY, Im W, Roux B. Ion Permeation through the a-Hemolysin Channel: Theoretical Studies Based on Brownian Dynamics and Poisson-Nernst-Plank Electrodiffusion Theory. Biophys J. 2004; 87:2299-2309. [PubMed: 15454431]

44. Grober RD, Acimovic J, Schuck J, Hessman D, Kindlemann PJ, Karrai K, Tiemann I, Manus S. Fundamental Limits to Force Detection Using Quartz Tuning Forks. Rev Sci Instrum. 2000; 71:2776-2780.

45. Friedt JM, Barry E. Introduction to the Quartz Tuning Fork. Am J Phys. 2007; 75:415-422.

46. Edwards H, Taylor L, Duncan W, Melmed AJ. Fast Low-cost Phase Detection Setup for TappingMode Atomic Force Microscopy. Rev Sci Instrum. 1997; 70:3614-3619.

47. King GM, Lamb JS, Nunes GJ. Quartz Tuning Forks as Sensors for Attractive-Mode Force Microscopy under Ambient Conditions. Appl Phys Lett. 2001; 79:1712-1714.

48. Hyun, C.; Kaur, H.; McNabb, DS.; Li, J. Stretching Tethered DNA on a SPM Tip by Dielectrophoresis. $\mathrm{p}$ In preparation

49. Kim K, Seo Y, Jang H, Chang S, Hong MH, Jhe W. Shear-Mode Magnetic Force Microscopy with a Quartz Tunning Fork in Ambient Conditons. Nanotechnology. 2006; 17:S201-S204. [PubMed: 21727415]

50. Egerton, RF. Electron Energy-Loss Spectroscopy in the Electron Microscope. Plenum Press; New York and London: 1996. 

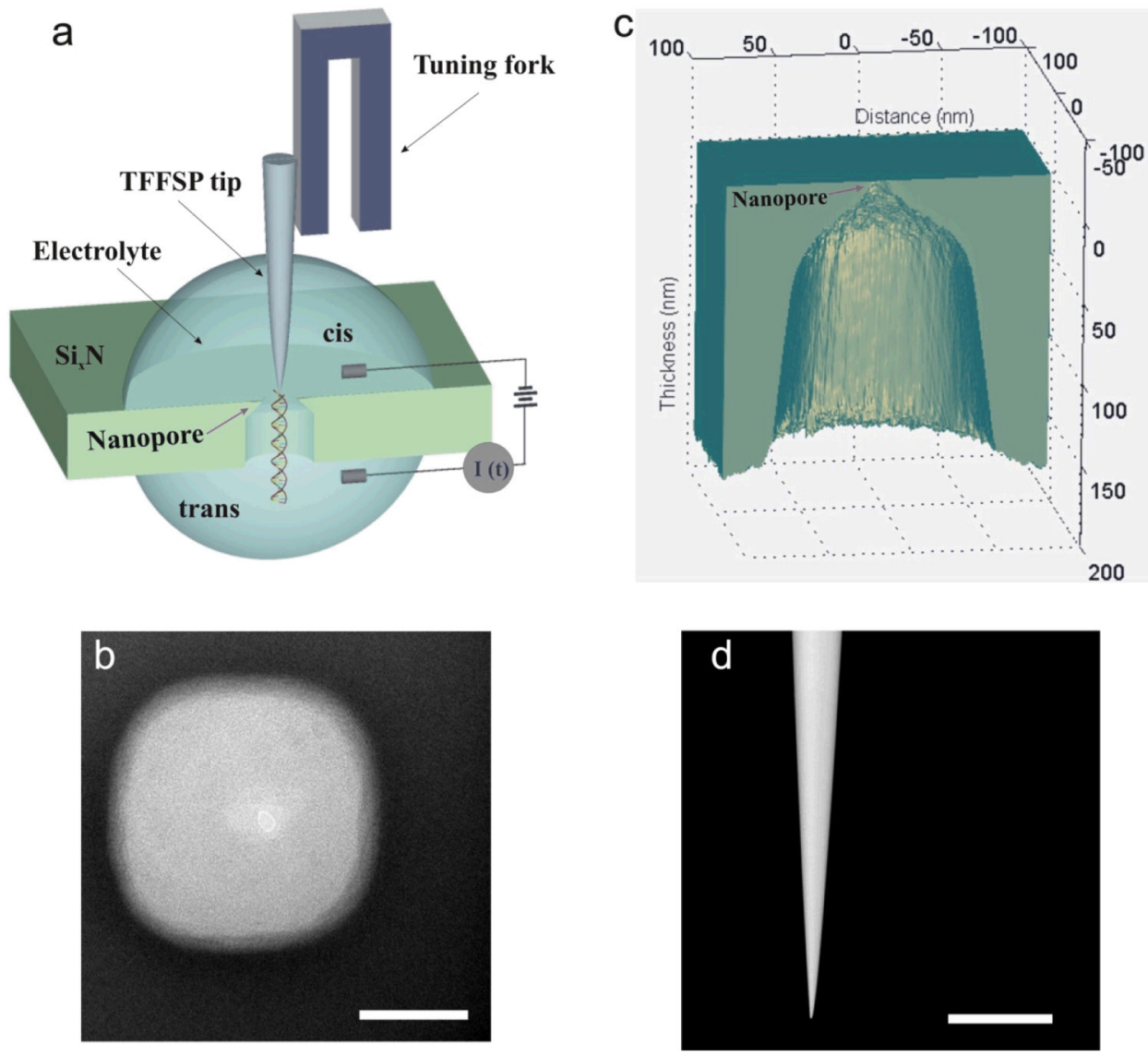

Figure 1.

(a) Diagram of the SSN-TFFSP experimental setup (not to scale). A $\lambda$ DNA is tethered to the TFFSP tip through biotin-streptavidin bonding. The optical fiber tip is glued to one of the prong of a tuning fork that is attached to a piezo actuator. The piezo actuator is controlled by a XYZ piezo positioner (not shown) that controls the location of the tip. (b) TEM image of a nanopore used in this work. The scale bar in the image is $50 \mathrm{~nm}$ long. (c) Thickness profile across the nanopore shown in Figure (b). (d) SEM image of an optical fiber tip coated with $\mathrm{Cr} / \mathrm{Au}$ used in this work. The scale bar is $20 \mu \mathrm{m}$ long. 
Possible configurations of the tip, DNA molecules, and the nanopore

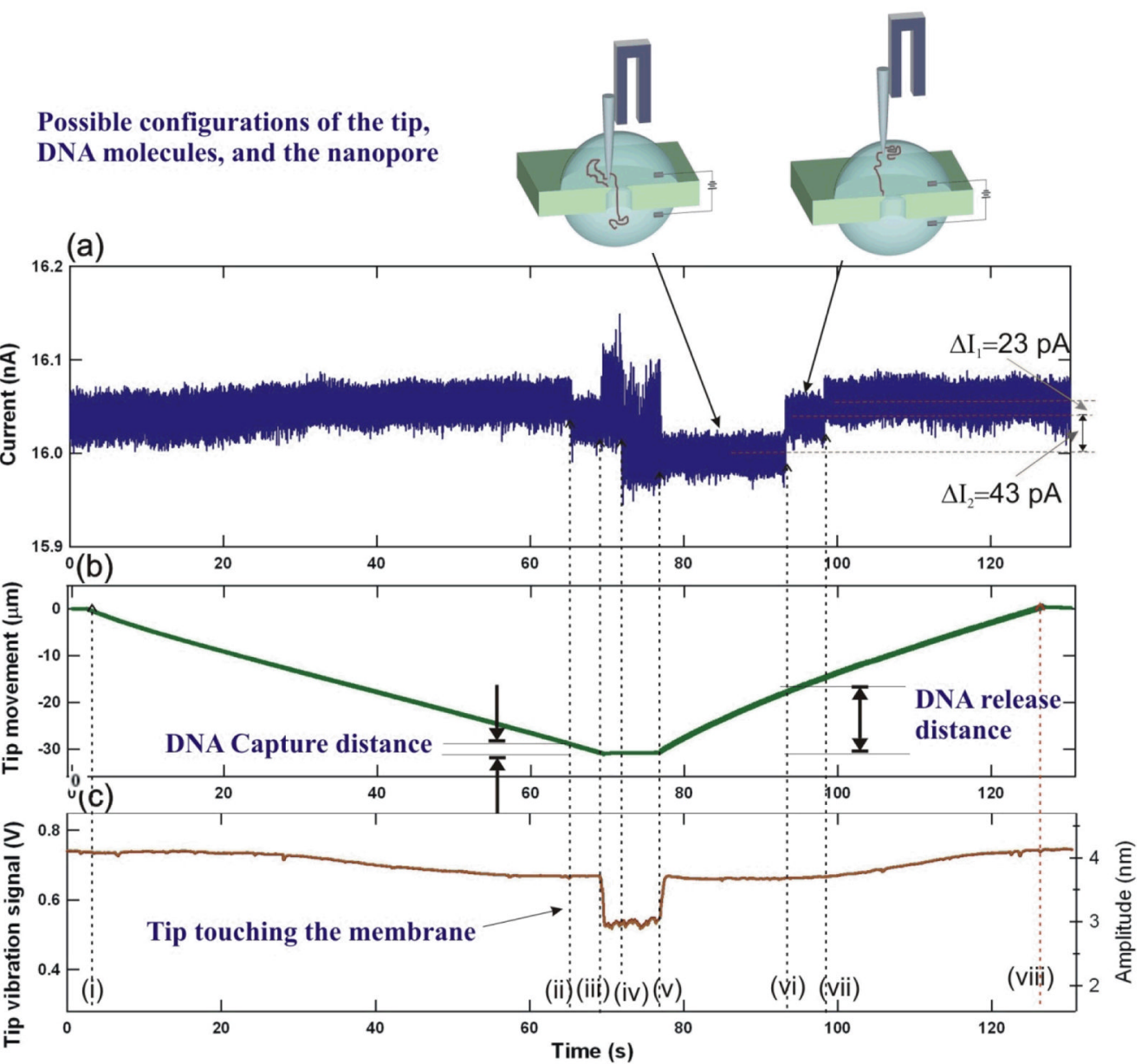

Figure 2.

Parameters measured in the SSN-TFFSP apparatus. (a) Current through the nanopore shown in Fig. $1 \mathrm{~b}$ in $1 \mathrm{M} \mathrm{KCl}$ solution with $60 \mathrm{mV}$ bias voltage. Current dropped when DNA molecules were captured by the nanopore, and current recovered to its original value when the DNA was released from the nanopore. (b) The TFFSP tip's movement. (c) The tuning fork's voltage signal after 1000 times amplification as the tip approaching and lifting from the nanopore surface. The right axis is the vibration amplitude converted by $0.18 \mathrm{~V} / \mathrm{nm}$. 

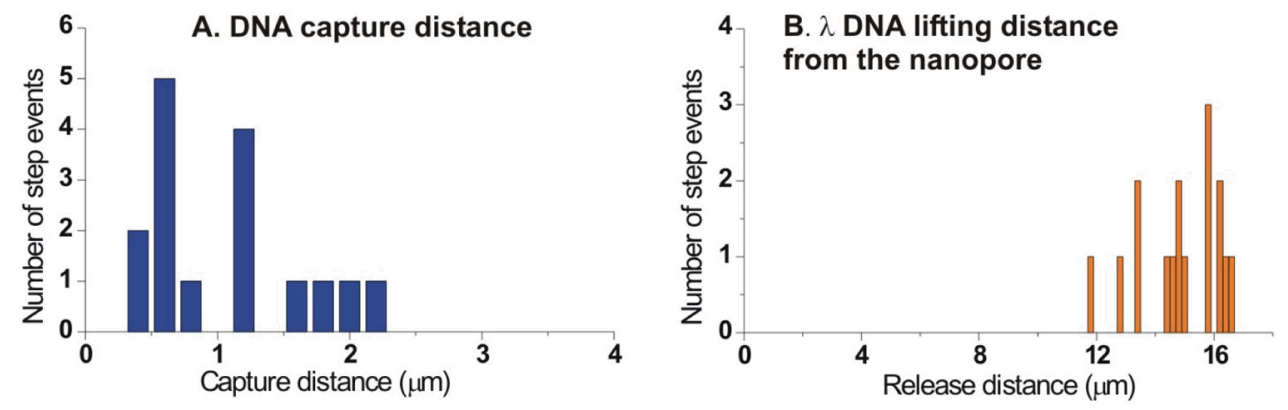

Figure 3.

The capture and release distance of $\lambda$ DNA. (a) DNA's $1^{\text {st }}$ capture distance from the tip's end to the membrane surface. The capture distance is comparable to $\lambda$ DNA's gyration radius $(500 \mathrm{~nm})$. (b) DNA last release distance when a tip moved away from a nanopore. The averaged last release distance $(15.1 \mu \mathrm{m})$ is close to $\lambda$ DNA's contour length $(16.4 \mu \mathrm{m})$. Data from two more sets of similar experiments are added to this figure to increase the number of step events. 

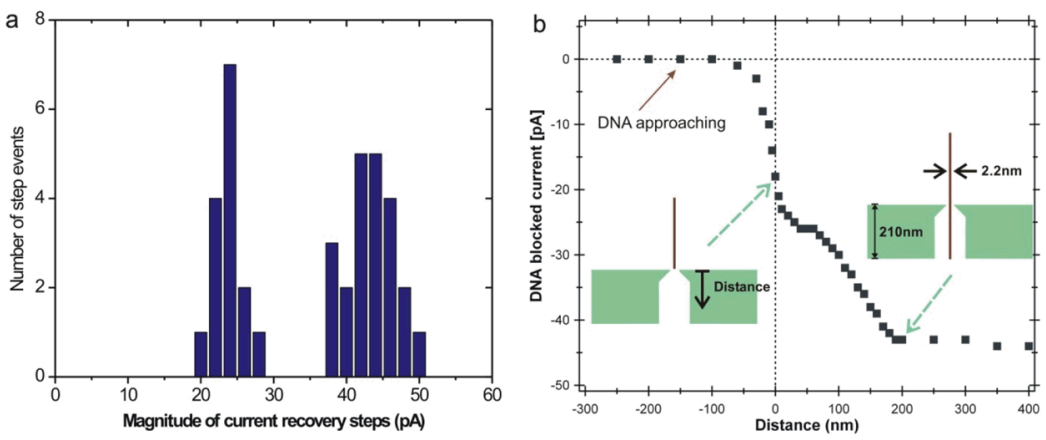

Figure 4.

(a) Amplitudes of current recovery step when DNA was pulled up from the nanopore. (b) COMSOL simulation of current blockage by dsDNA vs DNA-nanopore distance. Geometry of the nanopore is referred to the thickness profile shown in Fig. 1(c) and its diameter is 26 $\mathrm{nm}$. DNA is considered as an insulating $2.2 \mathrm{~nm}$ diameter cylinder rod. The distance is from the end of the cylinder rod to the top surface of a membrane as shown in the inset. The open pore current for $1 \mathrm{M} \mathrm{KCl}$ is $\mathrm{I}_{0}=14.9 \mathrm{nA}$ in this simulation. 


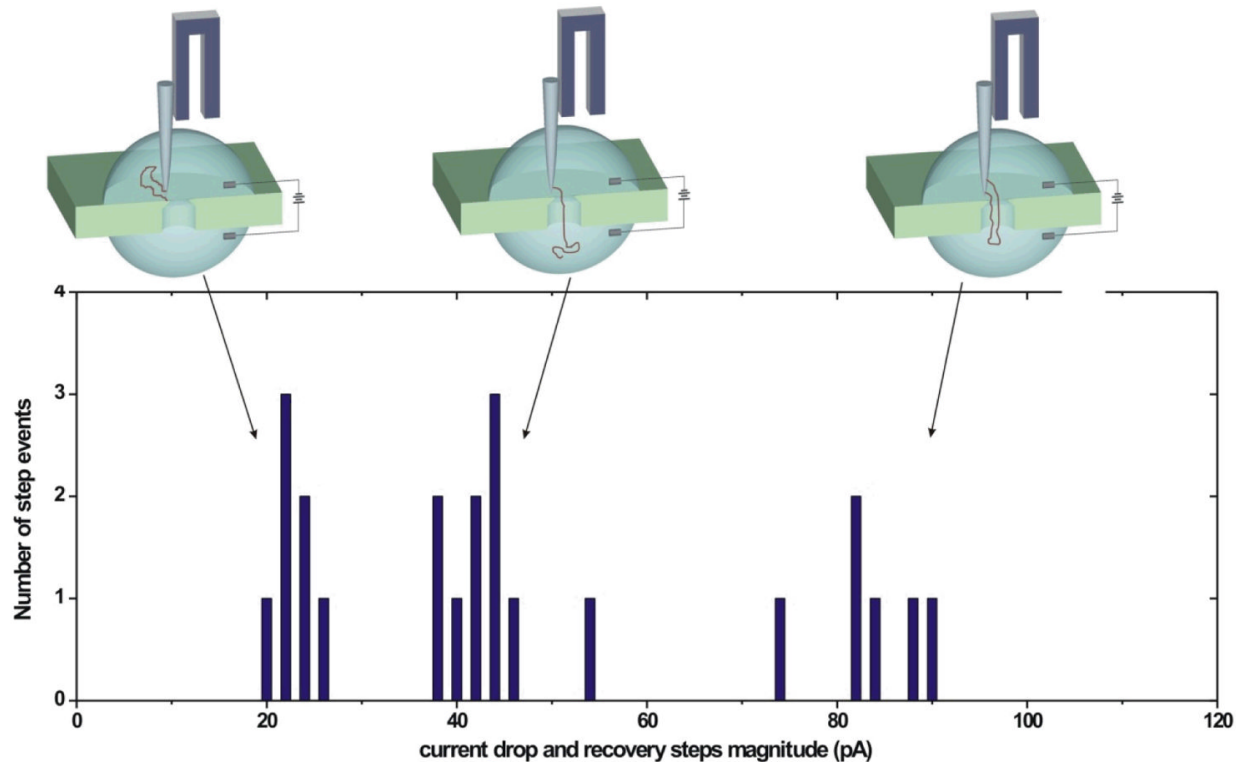

Figure 5.

Current drop amplitudes when some of the $\lambda$ DNA molecules are both-ends biotinylated. Two sets of data were recorded from two nanopores. One had an open pore current $\mathrm{I}_{0}=23.4$ $\mathrm{nA}$ and the other had $\mathrm{I}_{0}=13.0 \mathrm{nA}$. 